\title{
Silent ischaemia in diabetic men with autonomic neuropathy
}

\author{
J J O’Sullivan, R M Conroy, K MacDonald, T J McKenna, B J Maurer
}

\begin{abstract}
Autonomic neuropathy is associated with an increased incidence of silent myocardial infarction and sudden death. The purpose of this study was to investigate the prevalence of silent myocardial ischaemia in diabetic patients with autonomic neuropathy and without. Five standard autonomic function tests were performed on 41 men with diabetes: postural change in blood pressure, postural change in heart rate, heart rate response to deep breathing, heart rate response to Valsalva's manoeuvre, and blood pressure response to sustained handgrip. There were 17 patients with autonomic neuropathy (group A) and 24 with normal autonomic function (group B). All patients underwent 24 hour ambulatory electrocardiographic monitoring to detect silent ischaemia. There was no significant difference in risk factors for coronary artery disease or history of angina pectoris between these groups. The prevalence of silent ischaemia was $64.7 \%$ in group A $(95 \%$ confidence interval $(95 \% \mathrm{CI}) 38 \cdot 33$ to $85 \cdot 79 \%)$ and $4 \cdot 1 \%$ in group B (95\% CI $0 \cdot 11$ to $21 \cdot 12 \%)$. This represents a relative risk of $42 \cdot 2$ (95\% CI 4.5 to $39.4, p<0.001)$. These results are consistent with the concept that autonomic neuropathy may prevent the development of anginal pain and thus obscure the presence of ischaemic heart disease.

Twenty four hour ambulatory electrocardiographic monitoring may identify a subgroup of diabetic patients with autonomic neuropathy who have myocardial ischaemia and to whom treatment may be offered.
\end{abstract}

Departments of Cardiology and Endocrinology, St Vincent's Hospital Dublin, Ireland J J O'Sullivan R M Conroy K MacDonald T J McKenna B J Maurer

Correspondence to Dr J J O'Sullivan, Department of Paediatric Cardiology, Freeman Hospital, High Heaton Newcastle upon Tyne NE7 7DN.

Accepted for publication 29 April 1991
Clinical evidence of autonomic neuropathy in patients with diabetes mellitus is associated with increased mortality. ${ }^{1}$ Many of these deaths are sudden and may be due to myocardial ischaemia. ${ }^{23}$ Asymptomatic (silent) myocardial infarction is more common in
Table 1 Grading of autonomic function tests diabetic patients with autonomic neuropathy than in those without neuropathy ${ }^{4}$ but the prevalence of silent myocardial ischaemia is unknown. The purpose of this study was to investigate the prevalence of silent ischaemia, as detected by ambulatory electrocardiographic monitoring, in diabetic men with and without autonomic neuropathy.

\section{Patients and methods}

Forty four diabetic men who were recruited from the diabetic clinic, ophthalmology unit, and general medical wards of St Vincent's Hospital participated in the study. We excluded women; men younger than 40 years; patients with an abnormal resting electrocardiogram (bundle branch block, atrial fibrillation, or ST segment abnormalities); patients taking digitalis, $\beta$ blockers, or antidepressant medication; patients confined to bed; patients unable to give informed consent; patients with myocardial infarction or unstable angina within the past three months; and patients unable adequately to perform the autonomic function tests. We questioned the patients about symptoms of impotence, diarrhoea, disordered sweating, and postural dizziness. Physical examination and urinalysis were performed to identify complications of diabetes. The following five tests of autonomic function were performed and the responses graded as normal, borderline, or abnormal (table 1). (a) Systolic blood pressure response to standing. (b) Heart rate response to standing-The electrocardiogram was continually recorded as the patient went from lying to standing. After standing, the ratio of the longest $R R$ interval at around the 30th beat to the shortest $R R$ interval around the 15th beat was calculated. (c) Heart rate variation during deep breathingThe heart rate was continually recorded while the patient took six deep breaths over a period of one minute. The mean of the difference between the maximum and minimum heart rates was calculated.

(d) Heart rate response to Valsalva's manoeuvre-The patient blew into a mouthpiece connected to a sphygmomanometer and held

\begin{tabular}{|c|c|c|c|c|c|}
\hline & Valsalva's ratio & $\begin{array}{l}\text { Heart beat variation } \\
\text { during deep } \\
\text { breathing (beats/min) }\end{array}$ & $\begin{array}{l}\text { Immediate heart } \\
\text { rate lying to } \\
\text { standing (30:15) }\end{array}$ & $\begin{array}{l}\text { Increase in diastolic } \\
\text { blood pressures during } \\
\text { sustained handgrip }(\mathrm{mm} \mathrm{Hg})\end{array}$ & $\begin{array}{l}\text { Postural } \\
\text { hypotension } \\
\text { (mm Hg) }\end{array}$ \\
\hline $\begin{array}{l}\text { Normal } \\
\text { Borderline } \\
\text { Abnormal }\end{array}$ & $\begin{array}{l}>1 \cdot 20 \\
1 \cdot 11-1 \cdot 20 \\
\leqslant 1 \cdot 10\end{array}$ & $\begin{array}{l}>15 \\
11-15 \\
\leqslant 10\end{array}$ & $\begin{array}{l}>1.03 \\
1.10-1.03 \\
\leqslant 1.01\end{array}$ & $\begin{aligned}> & 15 \\
& 11-15 \\
\leqslant & 10\end{aligned}$ & $\begin{array}{l}\leqslant 20 \\
21-30 \\
>30\end{array}$ \\
\hline
\end{tabular}


it at a pressure of $40 \mathrm{~mm} \mathrm{Hg}$ for 15 seconds while the heart rate was continually recorded by electrocardiography. We calculated the ratio between the longest $R R$ interval after the manoeuvre to the shortest $R R$ interval during the manoeuvre.

(e) Blood pressure response to sustained handgrip-Diastolic blood pressure was measured during sustained handgrip every minute over a five minute period.

All patients had 24 hour ambulatory electrocardiographic monitoring. The ambulatory monitor used ( $Q$ Med Monitor One) contains a microprocessor that is connected through a single connector to one bipolar lead and a grounding electrode. Significant events were stored in a memory protected by a lithium battery. This system has been validated previously. ${ }^{56}$ After the electrodes were applied to the precordium a control strip was run for one minute to ensure that signals were satisfactory. The microprocessor was programmed to detect a horizontal or downsloping ST segment of $1 \mathrm{~mm}$ or more occurring $60 \mathrm{~ms}$ after the J point and persisting for at least 40 s. When the monitoring period was complete we obtained a sample of each ischaemic event and confirmed the presence of ST segment depression. We measured the number of ischaemic episodes and the total duration of ischaemia, if present, in each patient.

Statistical analysis was performed using the IBM SAS system. Differences between means were assessed for significance by the $t$ test, and those between proportions by the $\chi^{2}$ or, in the case of low observed frequencies, Fisher's exact test. Relative risks and their $95 \%$ CIs were calculated by the Mantel-Haenszel method as implemented in SAS version 5 ? $^{7}$

\section{Results}

ASSESSMENT OF AUTONOMIC FUNCTION IN DIABETIC MEN

Seventeen patients had at least two abnormal tests and these were designated as having definite autonomic neuropathy (group A). All tests were normal in 24 patients (group B). Three patients with a borderline abnormality in only one test were excluded from further study because they could not be classified as definitely normal or abnormal. The 17 patients with definite autonomic neuropathy had at least two abnormal parasympathetic function tests. All 17 patients had an abnormal heart rate response to standing and deep breathing. Seven subjects had an abnormal response to Valsalva's manoeuvre and five had a borderline result. Only three patients had abnormal sympathetic function (blood pressure response to standing and sustained handgrip), confirming the findings of others ${ }^{89}$ that sympathetic dysfunction occurs late and virtually always in the presence of abnormal parasympathetic function tests.

CLINICAL CHARACTERISTICS OF PATIENTS WITH AND WITHOUT AUTONOMIC NEUROPATHY

We found no significant differences in age, smoking history, history of hypertension, family history of coronary artery disease, or mean cholesterol concentration between diabetic patients with autonomic neuropathy and without (table 2). Forty one per cent of both groups had a history of angina pectoris. Angina was mild in all patients (grades I or II) except for one patient in group A with grade III symptoms (New York Heart Association). There was no significant difference in antianginal treatment between the groups, with $40 \%$ of the neuropathic group and $33 \%$ of the nonneuropathic group on either long acting nitrates or calcium channel blockers.

Patients with autonomic neuropathy tended to have had diabetes longer and had more complications than patients without autonomic neuropathy but these differences were not statistically significant. Five patients with autonomic neuropathy had no clinical evidence of peripheral neuropathy, retinopathy, or nephropathy. Fifty eight per cent of the neuropathic group had symptoms that could be attributed to autonomic dysfunction.

\section{SILENT MYOCARDIAL ISCHAEMIA IN DIABETIC PATIENTS WITH AND WITHOUT AUTONOMIC NEUROPATHY}

Patients with autonomic neuropathy had a significantly higher incidence of silent ischaemia than patients without. Eleven patients with autonomic neuropathy showed episodes of silent ischaemia, whereas only one patient without neuropathy did so, representing a relative risk of $42 \cdot 2(95 \%$ CI $4 \cdot 5$ to $39 \cdot 4$,

Table 2 Clinical characteristics of patients with (group A) and without (group B) autonomic neuropathy

\begin{tabular}{lccl}
\hline Characteristics & $\begin{array}{l}\text { Group } A \\
(n=17)\end{array}$ & $\begin{array}{l}\text { Group } B \\
(n=24)\end{array}$ & $p$ Value \\
\hline Age (yr, mean) & 61 & $61 \cdot 3$ & $0 \cdot 8359$ \\
Cigarette smokers (\%) & $9(53)$ & $11(45 \cdot 8)$ & $0 \cdot 654$ \\
Mean cholesterol (mm/1) & $5 \cdot 6$ & $5 \cdot 2$ & $0 \cdot 3086$ \\
Family history of coronary disease (\%) & $4(23 \cdot 5)$ & $4(16 \cdot 6)$ & $0 \cdot 587$ \\
Hypertension (\%) & $8(47)$ & $9(37 \cdot 5)$ & $0 \cdot 541$ \\
Previous myocardial infarction (\%) & $7(41)$ & $9(37 \cdot 5)$ & $0 \cdot 812$ \\
History of angina pectoris (\%) & $7(41)$ & $10(41 \cdot 6)$ & $0 \cdot 975$ \\
No history of coronary artery disease (\%) & $8(47)$ & $12(50)$ & $0 \cdot 853$ \\
On insulin therapy (\%) & $6(35 \cdot 3)$ & $12(50)$ & $0 \cdot 350$ \\
On oral hypogycaemic agents (\%) & $7(41)$ & $10(41 \cdot 6)$ & $0 \cdot 975$ \\
Controlled on diet only (\%) & $4(23 \cdot 5)$ & $2(8 \cdot 3)$ & $0 \cdot 212$ \\
Mean duration of diabetes (yr) & $8 \cdot 9$ & $6 \cdot 2$ & $0 \cdot 295$ \\
Total No of patients with diabetic complications (\%) & $12(70 \cdot 5)$ & $12(50)$ & $0 \cdot 187$ \\
Peripheral neuropathy (\%) & $11(64 \cdot 7)$ & $9(37 \cdot 5)$ & $0 \cdot 086$ \\
Nephropathy (\%) & $3(17 \cdot 6)$ & $2(18 \cdot 3)$ & $0 \cdot 633$ \\
Retinopathy (\%) & $7(41)$ & $8(33 \cdot 3)$ & $0 \cdot 607$ \\
\hline
\end{tabular}


p $<0.001)$. A total of 89 ischaemic episodes occurred, with an average duration of 4.8 minutes in 11 patients with autonomic neuropathy. During the monitoring period there were three episodes of angina in these patients with autonomic neuropathy. One patient with normal autonomic function showed silent ischaemia and had a further episode of angina over the period of monitoring. He had two symptomless episodes of ST segment depression, total duration two minutes. Six of the patients with silent ischaemia in group A had no history of angina pectoris but two had evidence of old infarction on the electrocardiogram. Therefore, four patients with autonomic neuropathy had unsuspected ischaemia.

\section{Discussion}

The autonomic nervous system controls the activity of the heart, blood vessels, and smooth muscle throughout the body. Relatively simple and reproducible bedside tests can assess the functional integrity of the sympathetic and parasympathetic divisions. ${ }^{1011}$ In diabetes mellitus damage to the parasympathetic system tends to occur early whereas clinical evidence of dysfunction of the sympathetic system is found later and is often associated with symptoms. Diabetic patients with symptoms and clinical evidence of autonomic neuropathy have a grave prognosis. ${ }^{1}$ In one prospective study of 73 patients with abnormal autonomic function tests a $56 \%$ mortality at five years was reported. ${ }^{1}$ Twenty eight per cent of the deaths were sudden and the exact mechanism of death was not clear. The importance of coronary artery disease in the diabetic population is well recognised and an increased incidence of silent myocardial infarction has been reported. Abnormalities in the autonomic fibres to the heart were found at necropsy in patients dying of painless myocardial infarction. ${ }^{12}$ Evidence of myocardial infarction has not been found at necropsy in many of the sudden deaths in patients with autonomic neuropathy ${ }^{12}$ but this may not be surprising as evidence of fresh infarction is rare in patients with coronary heart disease dying suddenly.

It is well known that episodes of myocardial ischaemia may occur without clinical symptoms. Erikssen drew attention to the prognostic significance of asymptomatic ischaemic changes detected by exercise testing. In a screening study 50 non-diabetic men with silent ischaemia were identified and nine of these died over a follow up of 13.5 years, all but one of them developing angina before death. ${ }^{1314}$ Ambulatory electrocardiographic monitoring is increasingly used to detect myocardial ischaemia. It is established that if patients on certain drugs and with normal resting electrocardiograms are excluded, ST segment depression correlates strongly with defects in myocardial perfusion. ${ }^{1516} \mathrm{~A}$ study in diabetic patients also found a good correlation between ST segment depression on ambulatory monitoring and positive exercise tests. ${ }^{17}$ Our study shows that silent ischaemia is significantly more common in diabetic men with autonomic neuropathy than in those without. Furthermore, we identified a group of patients with autonomic neuropathy in whom silent ischaemia was the only manifestation of coronary artery disease. We did not attempt to define the extent of coronary artery disease by arteriography in these patients and even though it would be interesting to do so we do not consider it clinically justifiable at the present time.

The increased incidence of sudden death in patients with diabetic autonomic neuropathy may well be related to their relative inability to perceive warning anginal pain. We have shown that silent ischaemia is common in such patients. Our observations provide an important initial data base against which the subsequent course of the expanding study population can be examined. This will permit the eventual outcome to be compared with the presence or absence of autonomic neuropathy and give important information on any association that may exist between silent ischaemia and subsequent mortality.

1 Ewing DJ, Cambell IW, Clarke BF. Mortality in diabetic autonomic neuropathy. Lancet 1976;i:601-3.

2 Ewing DJ, Cambell IW, Clarke BF. Assessment of cardiovascular effects in diabetic autonomic neuropathy and prognostic implications. Ann Intern Med 1980;92:308-11.

prognostic implications. Ann Intern Med 1980;92:308-11.
3 McB Page M, Watkins PJ. Cardiorespiratory arrest and diabetic autonomic neuropathy. Lancet 1978;i:14-6.

4 Niakan A, Harati Y, Rolak L, Comstock A, Rokey R. Silent myocardial infarction and diabetic autonomic neuropathy. myocardial infarction and diabetic auto

5 Barry J, Nabel E, Rocco MB, Campbell S, Selwyn AP. Validation of a device for ambulatory monitoring and on line analysis of ischaemia in patients with angin [abstract]. J Am Coll Cardiol 1986;7(suppl A):239A.

6 Garrett JS, Botvinich EH, Parmley WW, et al. Reliable assessment of myocardial ischaemia with a new EKG monitor [abstract]. Clin Res 1986;34:302A.

7 Cary NC. SAS user's guide. Statistics, version 5 edition. SAS Institute, 1985:418.

8 Ewing DJ, Clarke BF. Diagnosis and management of diabetic autonomic neuropathy. $B M J 1982 ; 285: 916-8$.

9 Bellavere F, Bosello G, Fedele D, Cardone C, Ferri M Diagnosis and management of diabetic autonomic neuropathy [letter]. BMJ 1983;287:61.

10 Hilsted J, Jensen S. A simple test for autonomic neuropathy in juvenile diabetes. Acta Med Scand 1979;205:385-7.

11 Ewing DJ, Cambell IW, Murray A, Neilson JM, Clarke BF. Immediate heart rate response to standing: simple test for Immediate heart rate response to standing: simple test for

12 Faerman I, Faccio E, Milei J, et al. Autonomic neuropathy and painless myocardial infarction in diabetic patients: and painless myocardial infarction in diabetic patients:
histological evidence of their relationship. Diabetes 1977;26:1147-58.

13 Erikssen J, Thaulow E. Follow up of patients with asymptomatic myocardial ischaemia. In: Rutishauser $\mathbb{W}$, Rosm H, eds Silent myocardial ischaemia. Berlin: Springer-Verlag, 1984:154-64.

14 Erikssen J. Prognostic importance of silent ischaemia during long term follow up of patients with coronary artery disease. Herz 1987;12:359-68.

15 Deanfield JE, Selwyn AP, Chierchia S, Maseri A, Ribeiro P, Krikler S. Myocardial ischaemia during daily life in patients with stable angina: its relation to symptoms and heart rate changes. Lancet 1983;i:753-8.

16 Deanfield JE, Shea M, Ribeiro P, et al. Transient STsegment depression as a marker of myocardial ischaemi during daily life. Am J Cardiol 1984;54:1195-200.

17 Chiarello M, Indolif C, Cotecchia M, Sifola C, Romano M, Condorelli M. Asymptomatic transient ST changes during ambulatory ECG monitoring in diabetic patients. $\mathrm{Am}$ Heart $J$ 1985;110:529-34. 